\title{
Same-different judgments of foveal and parafoveal letter pairs by older adults
}

\author{
LESTER E. KRUEGER and PHILIP A. ALLEN \\ Ohio State University, Columbus, Ohio
}

\begin{abstract}
Older adults (mean age: 67.9 years) judged whether two adjacent letters, presented either $0.5^{\circ}$ (foveal or near condition) or $2.0^{\circ}$ (parafoveal or far condition) from fixation, were identical or different. The method was identical to that used previously with young adults (Krueger, 1985). The older (and presumably noisier) adults were slower and less accurate in general, and, consistent with the internal-noise principle, they surpassed the young adults by showing a large, 48-msec fast-same effect and a large, $6 \%$ preponderance of false-different responses (i.e., errors on same trials) over false-same ones. With parafoveal presentation, the fast-same effect, but not the preponderance of false-different responses, increased greatly for the older adults, apparently due to an inability to perceive differing features (Eriksen, O'Hara, \& Eriksen's, 1982, missing-feature principle), owing to their more constricted visual fields (Cerella, 1985a). The fast-same effect was larger in the left visual field (right hemisphere) for young adults, but larger in the right visual field (left hemisphere) for older adults.
\end{abstract}

When people judge whether two letters are identical or not, same judgments typically are faster than different judgments (Krueger, 1978; Proctor, 1981). According to the noisy-operator theory (Krueger, 1978), internal noise more often changes physical matches into spurious perceived mismatches than vice versa. As a result, different judgments are slower, due to more rechecking of perceived mismatches, and there typically is a tendency to make more false-different responses (i.e., errors on same trials) than false-same ones.

The ability to account for the preponderance of falsedifferent errors distinguishes the internal-noise principle from other explanations of the fast-same effect, such as priming (Proctor, 1981), inhibition (Proctor, 1981), response competition (Eriksen, O'Hara, \& Eriksen, 1982), or missing features (Eriksen et al., 1982; Krueger \& Chignell, 1985), which seemingly would predict no difference in errors or else an excess of false-same responses. The latter models depict the different pair as the more difficult pair. Thus, presenting two different letters not only fails to allow one letter to facilitate the encoding of the other letter (priming principle), but may produce interference due to the activation of more than one naming response (inhibition principle). Furthermore, the mismatching features may not be detected early in processing (missing-feature principle), whereas the other, matching features may produce a tendency to respond "same" (response-competition principle). The internalnoise principle, by contrast, pinpoints the same pair as the more vulnerable pair and as the primary source of processing difficulty.

The authors are grateful to David B. Boles and Robert W. Proctor for helpful comments on an earlier version of this report. Requests for reprints should be sent to Lester E. Krueger, Human Performance Center, Ohio State University, 404-B West 17th Avenue, Columbus, OH 43210.
If the same pair is vulnerable under normal conditions, it should be even more vulnerable under more difficult or noisier conditions. Whether this increased vulnerability is expressed mainly in an increased fast-same effect or in an increased preponderance of false-different errors would depend on how the subjects adjust the criterion for rechecking versus responding (Krueger, 1985). If the criterion is adjusted properly, so that pairs with moderately large perceived difference counts are rechecked under the more difficult conditions, then both the fast-same effect and the preponderance of false-different errors will increase (Krueger \& Gott, 1985). However, if criterion inertia occurs, so that a criterion appropriate for normal processing is retained (i.e., pairs with small perceived difference counts are rechecked), then only the preponderance of false-different errors will increase (Krueger \& Shapiro, 1985).

Previous studies made processing more difficult by changing external conditions, for example, by using letter reversal and lateral masking (Krueger \& Gott, 1985) or by lengthening the interval between the successive presentation of the two patterns being compared (Krueger \& Shapiro, 1985). In the present study, by contrast, an internal factor was examined. Older adults were tested in order to determine whether the increased difficulty they experience would lead to performance consistent with the internal-noise principle, as have the studies that varied external conditions. Under normal conditions and with simultaneous presentation of the two letters, the fast-same effect for young adults typically is 20 to $40 \mathrm{msec}$, whereas the preponderance of false-different errors is $1 \%$ to $2 \%$ (Chignell \& Krueger, 1984; Krueger, 1985). If the internal-noise principle is valid, then older adults ought to show an increase on one or both of those effects, as well as a general increase in response time (RT) and errors. To measure the age-related effects more precisely, 
the present experiment, using older adults, was an exact replication of Krueger's (1985) experiment, which used young adults.

\section{Age-Related Deficits}

Many previous investigators have proposed, like us, that aging increases the level of spurious neural activity or internal noise, thereby reducing the signal-to-noise ratio and producing age-related deficits in perceptual tasks (Crossman \& Szafran, 1956; Gregory, 1959; Layton, 1975; Vickers, Nettelbeck, \& Willson, 1972; Welford, 1965, 1977). Older adults ( 60 years of age and above) typically are much slower than young adults (Botwinick, 1973), and a general, age-related slowing of processing has been proposed by Cerella (1985b) and Lindholm and Parkinson (1983), who found that, for a particular type of task, the ratio of RT for older versus young adults remained constant as task difficulty varied. Cerella said that older adults were only slightly slower on the sensorimotor components of a task, but about twice as slow as young adults on higher order components. Lindholm and Parkinson found a nearly constant slowing ratio of 1.4 for older (vs. young) adult RT on various tasks involving letter pairs, including physical matching.

In the present study, letter pairs sometimes were presented parafoveally $\left(2.0^{\circ}\right.$ from fixation) rather than foveally $\left(0.5^{\circ}\right)$, which should greatly increase the age deficit. Cerella (1985a) found that peripheral vision is constricted in elderly adults, and that "shifting a letter target from 0 to 2 deg doubled the age deficit in identification time" (p. 732). Thus, the parafoveal condition with older adults should greatly increase the task difficulty and thus the level of internal noise.

\section{Missing-Feature Principle}

Older adults are slower than young adults, but typically more cautious (Botwinick, 1973; Danziger, 1980) and sometimes more accurate (Lindholm \& Parkinson, 1983). In the present study, however, the letter pair was presented only briefly $(100 \mathrm{msec})$, and even if visual persistence lengthened the effective stimulus duration to perhaps 250 or $300 \mathrm{msec}$, the older adults would still be much more hard pressed than young adults to finish processing while the stimulus or its persistence was visible. Thus, the older adults might suffer as much from incomplete percepts as from distorted ones, especially with parafoveal presentation, given their more constricted visual fields.

If older adults treat the brief, faint percept as if it were an incomplete early percept, then the missing-feature principle, not the internal-noise principle, ought to predominate (Eriksen et al., 1982; Krueger \& Chignell, 1985), and false-same errors ought to outnumber falsedifferent errors. Apparently, letters tend to look very much alike early in processing. Different pairs often share many features, for example, EF, and "on the average, the percept will need to develop rather fully before a difference is detected" (Eriksen et al., 1982, p. 263). In early processing, the absence of a feature in one letter may simply be taken to indicate a delay in its arrival, and there- fore may not produce a spurious perceived mismatch between that letter and the other letter. Thus, under high speed stress, the usual error disparity reverses, so that false-same responses predominate (Krueger \& Chignell, 1985). If the present conditions limited the processing of the older adults in the same way, then the same error reversal ought to be found here. Both principles (missingfeature and internal-noise) predict faster same than different judgments, so no matter which predominates, a larger fast-same effect would be expected for older adults.

\section{Criterion Inertia}

The present replication with older adults provides an opportunity to confirm Krueger's (1985) finding of criterion inertia. Proper criterion adjustment requires that subjects allow for the greater prevalence of spurious perceived mismatches under difficult conditions, and that they greatly increase the perceived difference count tolerated for responding "same" and the count required for responding "different." In Krueger's study, proper criterion adjustment was evident on pure blocks of near (foveal) and far (parafoveal) trials, which both showed the typical fast-same effect and preponderance of falsedifferent errors. When near and far pairs were intermixed in his study, however, the fast-same effect increased and the preponderance of false-different errors decreased for near pairs, and vice versa for far trials. On mixed blocks, subjects evidently relied on a common, compromise criterion (recheck moderate perceived differences) instead of the separate, more appropriate criteria for near trials (recheck small differences) and far trials (recheck large differences) used on pure blocks.

\section{Subjects}

\section{METHOD}

Twenty older adults (11 male, 9 female; mean $[M]$ age $=67.9$ years; standard deviation $[S D]$ of age $=2.10$ ) were recruited from the Columbus, Ohio, community and were paid $\$ 5$ each for their participation. The 20 young adults (10 male, 10 female; median age: about 19 years) tested by Krueger (1985), had participated in order to receive credit in an introductory psychology course. The information subtest of the Wechsler Adult Intelligence Scale-Revised (WAIS-R), which correlates highly with WAIS-R Full Scale scores (Wechsler, 1981), was administered to the older adults. Their scores $(M=25.1 ; S D=2.53$; maximum possible score $=29)$ were significantly higher $[t(38)=5.60, p<.001]$ than those of a comparable group of 20 young adults who participated at about the same time in an unrelated study in our laboratory $(M=18.0, S D=5.03)$. Thus, the older adults were just as intelligent or knowledgeable as a typical group of young adults. Equivalent or superior performance of elderly adults on the information subtest is typical of the experience of the second author in testing young and older adults.

Like Krueger's (1985) young adults, all of the older adults had at least 20/30 (corrected) vision, as tested with a Snellen chart. None reported having cataracts. Handedness was nearly identical for the young and older adults. Nineteen of the 20 young adults had said they preferred the right hand, as did all 20 of the older adults. Krueger (1985) had excluded several additional young adults for disregarding the instruction to look at the fixation mark rather than far to the left or right, but none of the older subjects reported doing this. Data were excluded for one additional older adult, however, who could not do the task properly and reported being under neurological study. 
The rest of the method section is identical to that of Krueger (1985), and is repeated here for the convenience of the reader.

\begin{abstract}
Apparatus
Uppercase letters were presented at a $60-\mathrm{Hz}$ refresh rate and at $32 \mathrm{~cd} / \mathrm{m}^{2}$ intensity on a greenish-tint, fast-decay P31 phosphor (decay to $1 \%$ intensity at $.25 \mathrm{msec}$ after display offset) by an Imlac PDS-4 graphics computer, which also measured RT to an accuracy of 1 msec. The letters, presented as thin, illuminated lines on a dark screen, were software generated, using short line vectors, so as to resemble normal English uppercase letters. Each subject sat alone in a dark room, with the head held fast in a chinrest located $70 \mathrm{~cm}$ from the display screen.
\end{abstract}

\section{Stimulus Materials}

Letters were selected randomly from the set F, G, J, K, L, which are about equally discriminable from each other. Each letter was $0.29 \mathrm{~cm}$ wide and $0.43 \mathrm{~cm}$ high, and $.40 \mathrm{~cm}$ separated the two letters vertically. The pair thus was $1.26 \mathrm{~cm}\left(1.03^{\circ}\right)$ high. It was centered at the same height as, and located $.61 \mathrm{~cm}\left(0.5^{\circ}\right)$ or $2.44 \mathrm{~cm}$ $\left(2.0^{\circ}\right)$ to the left or right of, the fixation mark.

Each block of 144 trials contained 36 replicas of all combinations of the following factors: (1) visual field of letter pair (left, right), (2) trial type (same, different) $(36 \times 2 \times 2=144)$. One block of trials consisted of near pairs $\left(0.5^{\circ}\right.$ from fixation mark), a second block consisted of far pairs $\left(2.0^{\circ}\right.$ from fixation mark), and the other two blocks were mixed (i.e., 72 near pairs and 72 far pairs). The two mixed blocks were presented contiguously, either before ( 10 subjects) or after ( 10 subjects) the two pure blocks. Ten subjects received the near block before the far block; the other 10 had the reverse order. Four different randomized sequences of letter pairs and trials within blocks were used.

Each block consisted of four subblocks of 36 trials each. There was a 15-sec interval between subblocks, which allowed the next set of trials to be read in from the host computer. Each subblock was preceded by four practice trials, and there was a practice subblock (mixed distances) preceding the four regular blocks, for a total of 17 subblocks, or 680 trials (576 regular, 104 practice) in all.

\section{Procedure}

Each trial began with a .6-sec presentation of the fixation mark alone. The letter pair then appeared for $100 \mathrm{msec}$, followed by the fixation mark alone again until the subject responded. Feedback on response accuracy appeared in the upper part of the screen, directly above the fixation mark, during the 1.5-sec interval between trials. Subjects were instructed to keep their eyes focused at all times on the fixation mark, and to respond as rapidly as possible, but not at the expense of accuracy. They were cautioned that the letter pair would appear too briefly to let them move their eyes to focus on it.

Ten subjects pressed a right-hand button for same judgments and a left-hand button for different judgments; the other 10 had the reverse hand assignment. Trials with an RT greater than $3 \mathrm{sec}$ or less than $200 \mathrm{msec}$ were discarded prior to data analysis. Mean RT was computed for correct trials only.

\section{RESULTS AND DISCUSSION}

The main data for young adults (Krueger, 1985) and older adults are presented in Table 1 . The older adults were $137 \mathrm{msec}$ slower than the young adults $[F(1,38)=$ $11.92, p<.01]$ and $7.13 \%$ higher on errors $[F(1,38)=$ $31.50, p<.001]$. Parafoveal (vs. foveal) presentation hurt older adults more than young adults; the error effect was larger by $8.19 \%[F(1,38)=44.57, p<.001]$, whereas the RT effect was larger by $31 \mathrm{msec}$, but not significantly so $[F(1,38)=2.53]$. Consistent with the general
Table 1

Mean Response Time (RT; in Milliseconds), Mean Standard Deviation of Response Time ( $S D$; in Milliseconds), and Percentage of Error Rate (PE) by Distance from Fixation $\left(.05^{\circ}, 2^{\circ}\right)$, Block Type (Pure, Mixed), and Trial Type (Same, Different) for Young Adults (Data from Krueger, 1985) and Older Adults

\begin{tabular}{|c|c|c|c|c|c|c|}
\hline \multirow{3}{*}{$\begin{array}{l}\text { Distance and } \\
\text { Block Type }\end{array}$} & \multicolumn{6}{|c|}{ Trial Type } \\
\hline & \multicolumn{3}{|c|}{ Same } & \multicolumn{3}{|c|}{ Different } \\
\hline & RT & $S D$ & PE & RT & $S D$ & $\mathrm{PE}$ \\
\hline \multicolumn{7}{|c|}{ Young Adults } \\
\hline $\begin{array}{l}0.5^{\circ}, \text { pure } \\
0.5^{\circ} \text {, mixed } \\
2.0^{\circ} \text {, pure } \\
2.0^{\circ} \text {, mixed }\end{array}$ & $\begin{array}{l}598 \\
612 \\
676 \\
692\end{array}$ & $\begin{array}{l}147 \\
175 \\
202 \\
209\end{array}$ & $\begin{array}{l}3.76 \\
3.30 \\
6.27 \\
7.52\end{array}$ & $\begin{array}{l}619 \\
653 \\
690 \\
690\end{array}$ & $\begin{array}{l}152 \\
174 \\
195 \\
195\end{array}$ & $\begin{array}{l}2.29 \\
2.78 \\
4.24 \\
2.80\end{array}$ \\
\hline \multicolumn{7}{|c|}{ Older Adults } \\
\hline $\begin{array}{l}0.5^{\circ}, \text { pure } \\
0.5^{\circ} \text {, mixed } \\
2.0^{\circ} \text {, pure } \\
2.0^{\circ} \text {, mixed }\end{array}$ & $\begin{array}{l}704 \\
747 \\
787 \\
829\end{array}$ & $\begin{array}{l}158 \\
186 \\
215 \\
236\end{array}$ & $\begin{array}{r}9.14 \\
9.25 \\
19.39 \\
20.12\end{array}$ & $\begin{array}{l}724 \\
794 \\
860 \\
880\end{array}$ & $\begin{array}{l}132 \\
187 \\
198 \\
217\end{array}$ & $\begin{array}{r}3.33 \\
2.58 \\
14.81 \\
11.43\end{array}$ \\
\hline
\end{tabular}

slowing models of Cerella (1985b) and Lindholm and Parkinson (1983), mean RT was nearly a constant 1.2 times greater for older adults than for young adults on both the near and far trials.

However, errors increased much more on far (vs. near) trials for older adults (who made twice as many errors as young adults on near trials, but three times as many on far trials), which makes the constant ratio on RT less meaningful. The very brief $(100-\mathrm{msec})$ presentation apparently prevented older subjects from compensating for their slowness by taking more processing time. Lindholm and Parkinson, who presented the letter pair until the subject responded, found a slowing ratio of 1.4 for older adults, whose errors were slightly lower than those of young subjects.

The age $\times$ same versus different interaction was significant on errors $[F(1,38)=11.30, p<.01]$ and marginally significant on $\mathrm{RT}[F(1,38)=2.82, p \cong .10]$. The preponderance of false-different errors was $4.25 \%$ greater for older (and presumably noisier) adults, and the fastsame effect was 29 msec larger.

Thus, the predicted effects of internal noise were clearly evident and predominant. Nevertheless, the missingfeature principle, which predicts faster same judgments but more false-same errors, seemingly played some role with parafoveal presentation among older adults. For young adults, parafoveal presentation reduced the fastsame effect but increased the preponderance of falsedifferent errors, whereas for older adults it increased the fast-same effect and did not change the error disparity, apparently because the increase in missing features, due to their more constricted visual fields (Cerella, 1985a), about equaled the increase in internal noise. The age $x$ distance $X$ same versus different interaction was significant on RT $[F(1,38)=9.49, p<.01]$ but not on errors $(F<1)$. It should be noted that the greater preponderance of false-different errors for older adults was significant on the near trials analyzed separately $[F(1,38)=$ 
$13.46, p<.001]$ as well as the far trials $[F(1,38)=6.60$, $p<.025]$. Thus, the increase in internal noise with age was evident even with the relatively easy foveal presentation.

\section{Criterion Inertia}

For both the young and older adults, the fast-same effect increased and the preponderance of false-different errors decreased for near pairs, and vice versa for far pairs, when near and far trials were intermixed rather than blocked separately (see Table 1). Thus, most subjects, both young and old, tended to use a common, compromise criterion on mixed blocks, but criteria more appropriate for the two separate distances on pure blocks. The distance $\times$ same versus different $\times$ pure versus mixed interaction was significant on both RT $[F(1,38)=12.46$, $p<.01]$ and errors $[F(1,38)=5.74, p<.025]$. Age did not affect the latter interaction, on either RT $(F<1)$ or errors $(F<1)$. In a separate analysis for older adults, the interaction was significant on RT $[F(1,19)=7.24$, $p<.025]$ but not on errors $[F(1,19)=1.93]$.

\section{Standard Deviation of RT}

Same-different judgments typically are described solely in terms of RT and errors. The $S D$ of RT (which here was computed separately on each combination of conditions for each subject) rarely provides any new information, because it typically mimics RT; for example, it was higher on mixed (vs. pure) blocks $[F(1,38)=6.78$, $p<.025]$ and on far (vs. near) trials $[F(1,38)=27.98$, $p<.001$ ]. As shown in Table 1, however, it broke this rule by being significantly higher, not lower, on same (vs. different $)$ trials $[F(1,38)=6.28, p<.025]$. This divergence between the mean and $S D$ of RT is consistent with the internal-noise principle (see, e.g., Case 1, 1-sec ISI in Table 3 of Krueger, 1978, in which lower, but more variable, same than different $\mathrm{RT}$ was both observed and predicted). Processing time would be more variable for same pairs, for example, if half of the same pairs required no rechecking (fast RT) and the other half did (slow RT). Assuming that most different pairs require rechecking, different RT ought to be uniformly quite slow. In effect, processing is self-terminating on same trials, but largely exhaustive on different trials. Why, then, is greater variability on same (vs. different) RT found so rarely (Krueger, 1978, p. 291)? If processing time per step or stage varies (contrary to Krueger's, 1978, assumption of a fixed, 200-msec pass duration), then the $S D$ of RT would tend to be larger on different judgments, which have more steps. Only if the latter, within-step variability is relatively small, as Krueger (1978) assumed and as apparently was true for the young and older adults here, would the $S D$ be larger for same RT, owing to the self-termination factor (see Townsend \& Ashby, 1983, Proposition 7.7).

\section{Visual Field}

Mean RT was slightly ( $5 \mathrm{msec}$ ), but not significantly, lower for the left- than for the right-field pairs $[F(1,38)$ $=1.18]$, whereas errors were significantly $(1.06 \%)$ lower
$[F(1,38)=4.82, p<.05]$. Age did not interact with visual field on either RT $(F<1)$ or errors $(F<1)$; both young and older adults were slightly faster and more accurate on left-field pairs. As noted above, handedness was nearly identical for the young and older adults; virtually all preferred the right hand.

However, as shown in Table 2, the age $\times$ left versus right field $\times$ same versus different interaction was significant both on RT $[F(1,38)=8.30, p<.01]$ and $S D$ of RT $[F(1,38)=18.79, p<.001]$. Where the same RT was relatively low (left field for young adults; right field for older adults), so, too, was its relative variability. For young adults analyzed separately, the fast-same effect was larger in the left (vs. right) field, 34 versus $3 \mathrm{msec}$ $[F(1,19)=9.54, p<.05]$, whereas the increase in the $S D$ for same (vs. different) RT was smaller, -14 versus $23 \mathrm{msec}[F(1,19)=16.66, p<.001]$. Conversely, for older adults, the fast-same effect was smaller, but not significantly so, in the left (vs. right) field, 33 versus $63 \mathrm{msec}$ $[F(1,19)=3.23, p<.10]$, whereas the increase in the $S D$ for same (vs. different) RT was larger, 27 versus $4 \operatorname{msec}[F(1,19)=4.87, p<.05]$.

Thus, the processes favoring a fast-same effect seem to shift with age from the visual-spatial dominant right hemisphere (left visual field) to the language-dominant left hemisphere (right visual field). However, previous investigations with young subjects have not been consistent, and the present results ought to be treated with caution. With young subjects, Davis and Schmit (1973), like Krueger (1985), found a larger fast-same effect in the left than in the right visual field, but Bagnara, Boles, Simion, and Umiltà (1983) and Egeth and Epstein (1972) found just the opposite results, and other studies have found no difference between the two fields (Krueger \& Gott, 1985; Lefton \& Haber, 1974; Polich, 1982).

\section{Sequential Effects}

In a special analysis, the influence of the preceding trial type (same, different) also was considered. Response repetition (i.e., the preceding trial type matched the current one) decreased RT by $12 \mathrm{msec}[F(1,38)=5.19$, $p<.05]$ and errors by $0.68 \%$, although not significantly

Table 2

Mean Response Time (RT; in Milliseconds), Mean Standard

Deviation of Response Time (SD; in Milliseconds), and

Percentage of Error Rate (PE) by Visual Field (Left, Right), and Trial Type (Same, Different) for Young Adults (Data from Krueger, 1985) and Older Adults

\begin{tabular}{|c|c|c|c|c|c|c|}
\hline \multirow[b]{3}{*}{ Visual Field } & \multicolumn{6}{|c|}{ Trial Type } \\
\hline & \multicolumn{3}{|c|}{ Same } & \multicolumn{3}{|c|}{ Different } \\
\hline & RT & $S D$ & $\mathrm{PE}$ & RT & $S D$ & PE \\
\hline \multicolumn{7}{|c|}{ Young Adults } \\
\hline Left & 633 & 166 & 4.30 & 667 & 180 & 3.14 \\
\hline Right & 656 & 200 & 6.13 & 659 & 177 & 2.92 \\
\hline \multicolumn{7}{|c|}{ Older Adults } \\
\hline Left & 773 & 206 & 13.90 & 806 & 179 & 7.31 \\
\hline Right & 761 & 192 & 15.05 & 824 & 188 & 8.77 \\
\hline
\end{tabular}


Table 3

Pure Blocks Only: Mean Response Time (RT; in Milliseconds) and Percentage of Error Rate (PE) by Distance from Fixation $\left(0.5^{\circ}, 2.0^{\circ}\right)$, Successive Subblock Number, and Trial Type (Same, Different) for Young Adults (Data from Krueger, 1985) and Older Adults

\begin{tabular}{|c|c|c|c|c|c|c|c|c|}
\hline \multirow{3}{*}{$\begin{array}{c}\text { Subblock } \\
\text { Number }\end{array}$} & \multicolumn{4}{|c|}{ Young Adults } & \multicolumn{4}{|c|}{ Older Adults } \\
\hline & \multicolumn{2}{|c|}{ Same } & \multicolumn{2}{|c|}{ Different } & \multicolumn{2}{|c|}{ Same } & \multicolumn{2}{|c|}{ Different } \\
\hline & $\overrightarrow{\mathrm{RT}}$ & $\mathbf{P E}$ & RT & $\mathrm{PE}$ & RT & $\mathrm{PE}$ & RT & PE \\
\hline \multicolumn{9}{|c|}{ At $0.5^{\circ}$ Distance } \\
\hline $\begin{array}{l}1 \\
2 \\
3 \\
4\end{array}$ & $\begin{array}{l}590 \\
602 \\
610 \\
593\end{array}$ & $\begin{array}{l}6.85 \\
4.17 \\
2.00 \\
3.40\end{array}$ & $\begin{array}{l}635 \\
611 \\
645 \\
598\end{array}$ & & & & $\begin{array}{l}737 \\
728 \\
732 \\
703\end{array}$ & $\begin{array}{l}3.73 \\
2.64 \\
3.29 \\
4.21\end{array}$ \\
\hline \multicolumn{9}{|c|}{ At $2.0^{\circ}$ Distance } \\
\hline $\begin{array}{l}1 \\
2 \\
3 \\
4\end{array}$ & $\begin{array}{l}675 \\
713 \\
671 \\
671\end{array}$ & $\begin{array}{l}5.89 \\
7.11 \\
5.47 \\
6.59\end{array}$ & $\begin{array}{l}665 \\
714 \\
675 \\
698\end{array}$ & $\begin{array}{l}5.22 \\
3.42 \\
4.28 \\
4.07\end{array}$ & $\begin{array}{l}783 \\
764 \\
810 \\
806\end{array}$ & $\begin{array}{l}17.71 \\
19.64 \\
24.06 \\
18.92\end{array}$ & $\begin{array}{l}876 \\
856 \\
847 \\
879\end{array}$ & $\begin{array}{l}20.90 \\
13.22 \\
14.05 \\
11.33\end{array}$ \\
\hline
\end{tabular}

so $[F(1,38)=1.91]$. Response repetition aided older adults much more than young adults on errors $[F(1,38)$ $=4.58, p<.05]$ and, to a marginally significant extent, on $\operatorname{RT}[F(1,38)=2.89, p<.10]$. For older adults analyzed separately, response repetition reduced RT by $21 \mathrm{msec}[F(1,19)=6.61, p<.025]$ and errors by $1.73 \%[F(1,19)=4.33, p \cong .05]$, whereas for young adults it reduced RT by $3 \mathrm{msec}(F<1)$ and increased errors by $0.37 \%(F<1)$. The 13 -msec increase for $S D$ of $\mathrm{RT}$ on repetition (vs. nonrepetition) trials $[F(1,38)=$ $12.39, p<.01$ ] (young adults, $17 \mathrm{msec}$; older adults, $10 \mathrm{msec}$ ) suggests that the aid from repetition was an allor-none phenomenon, reducing RT much more on some trials than on others.

\section{Pure Blocks}

A second analysis was restricted to pure blocks, and examined changes occurring across the four successive, 36-trial subblocks that constituted each pure block. As shown in Table 3, RT did not vary across the four subblocks $(F<1)$, whereas errors decreased $[F(3,114)=$ $3.40, p<.025]$. However, the subblock factor interacted with distance $\times$ same versus different on errors $[F(3,114)$ $=5.05, p<.01]$. The decrease in errors across subblocks was restricted to same trials on near pairs and to different trials on far pairs (see Table 3). This is exactly opposite to the pattern expected if criterion adjustment to the near or far condition had progressively increased over the four subblocks. Instead, the criterion tended to revert to a common, compromise position, thus leading, as was true on mixed blocks, to a decrease in the preponderance of false-different errors on near trials and an increase on far trials. Conceivably, the subjects overshot the correct criterion adjustment in the initial subblock, and simply reverted to a less extreme, but more appropriate, setting on the subsequent subblocks. Fatigue from maintaining the more extreme settings also may have encouraged the criterion erosion.

\section{CONCLUSIONS}

The older adults were, indeed, noisier than the young adults, as indicated by the 1.2 slowing ratio on RT and a more than doubling of errors. Consistent with the internal-noise principle, older adults showed larger same versus different effects than did young adults. The 48-msec fast-same effect and $6 \%$ preponderance of false-different errors shown by the older adults are nearly as outsized as the $67-\mathrm{msec}$ fast-same effect and $9 \%$ error disparity that Krueger and Gott (1985) found with young adults under difficult conditions (brief, parafoveal, laterally masked presentation). However, the missing-feature principle, which predicts faster same RT but more false-same errors, also seems to have held with parafoveal presentation for the older adults. The preponderance of falsedifferent errors remained constant, whereas the fast-same effect doubled with parafoveal presentation for the older adults. This suggests that the two principles (missingfeature, internal-noise) contributed about equally to the parafoveal effects. Parafoveal presentations are not only noisier, but also, apparently, less visible for older adults, due to their more constricted visual fields (Cerella, 1985a).

The fact that the RT and error disparity on same versus different increased under difficult conditions and with older adults does not prove, of course, that internal noise plays a major role under normal conditions with young adults, although it might well explain the modest, 20- to $40-\mathrm{msec}$ fast-same effect and the $1 \%$ to $2 \%$ preponderance of false-different errors normally found with simultaneous presentation. Testing the internal-noise principle under difficult conditions and with older adults is important, nevertheless, because if neither the RT nor error disparity were to increase in such cases, the principle certainly could not be applied in the normal case. Furthermore, many or most perceptual encounters occur under difficult conditions or involve older adults, so findings obtained in such cases have as much as or more relevance for understanding everyday perception than those obtained with college sophomores under more normal (i.e., easier) laboratory conditions.

An important, unanswered question is the locus of the increased internal noise in older adults. The fast-same effect was larger in the left visual field (right hemisphere) for young adults, but larger in the right visual field (left hemisphere) for older adults. This suggests that aging increases the level of internal noise primarily in the left (language-dominant) hemisphere.

\section{REFERENCES}

Bagnara, S., Boles, D. B., Simion, F., Umiltà, C. (1983). Symmetry and similarity effects in the comparison of visual patterns. Perception \& Psychophysics, 34, 578-584. 
Botwinick, J. (1973). Aging and behavior: A comprehensive integration of research findings. New York: Springer.

Cerella, J. (1985a). Age-related decline in extrafoveal letter perception. Joumal of Gerontology, 40, 727-736.

Cerella, J. (1985b). Information processing rates in the elderly. Psychological Bulletin, 98, 67-83.

Chignell, M. H., \& Krugger, L. E. (1984). Further evidence for priming in perceptual matching: Temporal, not spatial, separation enhances the fast-same effect. Perception \& Psychophysics, 36, 257-265.

Crossman, E. R. F. W., \& Szafran, J. (1956). Changes with age in the speed of information intake and discrimination. Experientia Supplementum, 4, 128-135.

DANZIGER, W. L. (1980). Measurement of response bias in aging research. In L. W. Poon (Ed.), Aging in the 1980s: Psychological issues (pp. 552-557). Washington, DC: American Psychological Association.

DAvis, R., \& Schmit, V. (1973). Visual and verbal coding in the interhemispheric transfer of information. Acta Psychologica, 37, 229-240.

Egeth, H., \& Epstein, J. (1972). Differential specialization of the cerebral hemispheres for perception of sameness and difference. Perception \& Psychophysics, 12, 218-220.

Eriksen, C. W., O'Hara, W. P., \& Eriksen, B. A. (1982). Response competition effects in same-different judgments. Perception \& Psychophysics, 32, 261-270.

GREGORY, R. L. (1959). "Neurological noise" as a factor in aging. Proceedings of the Fourth Congress of the International Association of Gerontology, 1, 314-324.

KRUeger, L. E. (1978). A theory of perceptual matching. Psychological Review, 85, 278-304.

KRUEGER, L. E. (1985). Effect of intermixed foveal and parafoveal presentation on same-different judgments: Evidence for a criterioninertia model. Perception \& Psychophysics, 37, 266-271.

KRUEGER, L. E., Chignell, M. H. (1985). Same-different judgments under high speed stress: Missing-feature principle predominates in early processing. Perception \& Psychophysics, 38, 188-193.
Krueger, L. E., \& GotT, R. E. (1985). Effect of lateral masking and letter reversal on same-different judgments. Bulletin of the Psychonomic Society, 23, 185-188.

Krueger, L. E., \& Shapiro, R. G. (1985). Effect of interstimulus interval and heterogeneity of difference on same-different judgments of visual patterns. Bulletin of the Psychonomic Society, 23, 43-46.

Layton, B. (1975). Perceptual noise and aging. Psychological Bulletin, 82, 875-883.

Lefton, L. A., \& Haber, R. N. (1974). Information extraction from different retinal locations. Journal of Experimental Psychology, 102, 975-980.

Lindholm, J. M., \& Parkinson, S. R. (1983). An interpretation of age-related differences in letter-matching performance. Perception \& Psychophysics, 33, 283-294.

Polich, J. M. (1982). Hemispheric differences for visual search: Serial vs. parallel processing revisited. Neuropsychologia, 20, 297-307.

Proctor, R. W. (1981). A unified theory for matching-task phenomena. Psychological Review, 88, 291-326.

TownsEND, J. T., \& AsHBY, F. G. (1983). Stochastic modeling of elementary psychological processes. New York: Cambridge University Press.

Vickers, D., Nettelbeck, T., \& Willson, R. J. (1972). Perceptual indices of performance: The measurement of "inspection time" and "noise" in the visual system. Perception, 1, 263-295.

WELFORD, A. T. (1965). Performance, biological mechanisms and age: A theoretical sketch. In A. T. Welford \& J. E. Birren (Eds.), Behavior, aging and the nervous system (pp. 3-20). Springfield, IL: Thomas.

WELFORD, A. T. (1977). Motor performance. In J. E. Birren \& K. W. Schaie (Eds.), Handbook of the psychology of aging (pp. 450-496). New York: Van Nostrand Reinhold.

WeCHSLER, D. (1981). Manual for the Wechsler Adult Intelligence ScaleRevised. New York: Psychological Corporation.

(Manuscript received September 25, 1986; revision accepted for publication December 23, 1986.) 